\title{
Pesquisando as compositoras brasileiras no século XXI
}

[Researching the female Brazilian composers in the 2Ist century

\section{Ana Carolina Arruda de Toledo Murgel ${ }^{\mathrm{I}}$}

RESUMO - O presente artigo foca as motivações, os resultados, a metodologia e a utilização da tecnologia, arquivos e fontes na construção e desenvolvimento da pesquisa "Cartografias da canção feminina: compositoras brasileiras do século XX" desenvolvida com apoio da Fundação de Amparo à Pesquisa do Estado de São Paulo (Fapesp) no pós-doutorado em História Cultural no Departamento de História do Instituto de Filosofia e ciências Humanas da Universidade Estadual de Campinas (IFCH/ Unicamp). • PALAVRAS-CHAVE • Composição feminina; música popular; compositoras brasileiras. ABSTRACT - This article focuses on the motivations, results, methodology and use of technology, archives and sources in the construction and development of the research "Cartographies of the female song: Brazilian composers of the 2oth century" developed with the support of Foundation for Research Support of the State of São Paulo (Fapesp) in postdoctoral studies in Cultural History in the Department of History of the Institute of Philosophy and Human Sciences of the State University of Campinas (IFCH/Unicamp). • KEYWORDS - Female composition; popular music; Brazilian composers

Recebido em 30 de março de 2018

Aprovado em 5 de outubro de 2018

MURGEL, Ana Carolina Arruda de Toledo. Pesquisando as compositoras brasileiras no século XXI. Revista do Instituto de Estudos Brasileiros, Brasil, n. 7I, p. I8I-I92, dez. 2018.

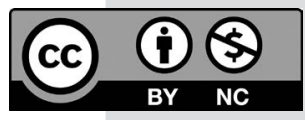

DOI: http://dx.doi.org/Io.II6o6/issn.23I6-90IX.voi7IpI8I-I92

I Universidade Estadual de Campinas (Unicamp, Campinas, SP, Brasil). 
Quando realizei minha pesquisa de mestrado sobre as compositoras da Vanguarda Paulista (MURGEL, 2005), fui indagada por vários colegas e em simpósios sobre outras compositoras brasileiras. $\mathrm{O}$ fato de escolher algumas delas como personagens de minha pesquisa chamou a atenção para a falta de conhecimento sobre a autoria feminina na canção popular. Nos cursos que ministrei no Departamento de História do Instituto de Filosofia e Ciências Humanas da Universidade Estadual de Campinas (IFCH/Unicamp) e em palestras, perguntava aos alunos e ouvintes se podiam citar de cabeça algumas delas, cinco, talvez. Algumas eram lembradas facilmente - as que estiveram de alguma forma em minisséries recentes, como Chiquinha Gonzaga ou Maysa. Nomes de outras compositoras que também são intérpretes, com produção extremamente rica e conhecida, como Rita Lee e Marina Lima, por exemplo, eram dificilmente lembrados.

$\mathrm{Na}$ época de graduação, o trabalho para sustentar minha vida era tocar em bares, e claro que sempre me interessei pelos compositores das músicas que cantava. Entendia que uma canção era como um poema ou um livro: se gostássemos, era evidente que deveríamos nos interessar por quem compôs, mas percebi rapidamente que, para o público que pedia canções, não era bem assim - são incontáveis as vezes que me pediram "London, London" do RPM ou "De noite na cama" de Marisa Monte (ambas de Caetano Veloso). São poucas as pessoas realmente interessadas nas autorias das composições, com mais frequência entendendo o intérprete como autor, o que é reforçado nos dias de hoje na maioria dos sites com letras de canções ligadas somente aos intérpretes ou nos programas escolhidos para ouvir canções on-line, como Spotify ou Youtube, com algumas exceções.

Esse desconhecimento não é exclusivo de nossas terras. Nos Estados Unidos, por exemplo, a maior parte das gravações tem seus autores (quando os tem) anotados apenas por iniciais ou pelo sobrenome, tornando difícil a busca de compositores ou do seu gênero. Ainda sobre essa questão, especificamente, Rita Lee já afirmava em "Pagu" que "minha mãe é Maria Ninguém", coberta de razão. A canção pode remeter à de Carlos Lyra, gravada em I960, mas creio que a compositora foi um pouco mais direta em relação ao trecho. As mulheres não têm sobrenomes, carregam sempre o nome dos homens, pais ou maridos, e mesmo o do pai é perdido nas gerações seguintes. A historiadora Michelle Perrot afirma que 
Pelo casamento, as mulheres perdiam seu sobrenome, o que ocorria na França, mas não somente aí. É bastante difícil, e mesmo impossível, reconstituir linhagens femininas. A pesquisa demográfica chamada TRA iniciada por Jacques Dupâquier, que estabeleceu a genealogia das famílias cujo patronímico começa por Tra, para estudar os fenômenos de mobilidade social, desistiu de incluir as mulheres por conta disso. (PERROT, 2007, p. 2I).

$\mathrm{Na}$ história isso se repete: como lembra a filósofa Jeanne Marie Gagnebin, mesmo quando se trata de dez mulheres e um homem, em português o plural fica no masculino, "eles" (GAGNEBIN, I982). Assim, as mulheres desapareceram nos estudos sobre, por exemplo, o movimento operário no início do século XX, lembrando que a maior parte das indústrias eram têxteis, e a maior parte dos "operários" eram na verdade operárias. Claro que há exceções entre historiadores, como os estudos de Margareth Rago, que dão a devida visibilidade às mulheres anarquistas e operárias (cf. RAGO, I985; 200I).

Ao me debruçar sobre as compositoras brasileiras, encontrei dois livros de pesquisadoras que também haviam feito o mesmo em meados dos anos de I980: Nós, as mulheres (notícias sobre as compositoras brasileiras), de Eli Maria Rocha (I986), e Mulheres compositoras: elenco e repertório, de Nilcéia Cleide da Silva Baroncelli (I987), ambas também compositoras. Elas levaram cerca de dez anos pesquisando em arquivos para publicar seus livros. Nilcéia Baroncelli levantou 2.400 compositoras no mundo inteiro, I80 das quais brasileiras, eruditas e populares. Eli Maria Rocha centrou sua pesquisa nas compositoras eruditas brasileiras, tendo levantado I74 delas. Em tempos de pesquisa somente em livros e arquivos, é evidente a dificuldade e, ao mesmo tempo, o sucesso obtido pelas duas pesquisadoras. Em meu próprio levantamento, utilizando a tecnologia da internet, com seus acervos digitais, além de discografias, dicionários, biografias, livros e artigos diversos, identifiquei cerca de 7,5 mil compositoras brasileiras. Minha proposta inicial era buscar somente as que iniciaram suas produções no século XX, mas parcerias entre compositoras expandiram a pesquisa para o século XXI, sendo o levantamento mais superficial, mas com a pretensão de continuidade assim que terminar a publicação do montante encontrado até o momento. E, ainda, alguns achados na Hemeroteca Digital da Biblioteca Nacional acabaram por levar a pesquisa também ao século XIX.

Com o montante encontrado, algumas das propostas iniciais do projeto de pesquisa tiveram que ser adiadas, como entrevistas com compositoras e detalhamento da obra na busca de uma poética feminista (cf. MURGEL, 20Io), já que o trabalho empírico se tornou muito extenso. Na pesquisa, foram privilegiados dados biográficos básicos - data e local de nascimento, nome completo e fontes para pesquisa. O que se apresentou, nesse primeiro momento, foi um rico arquivo de compositoras para os próximos passos de uma nova pesquisa e também para futuros pesquisadores, já que esse material está sendo publicado on-line juntamente com a indicação das fontes utilizadas (MURGEL, 20I8). A decisão pela publicação on-line levou em conta não somente a possibilidade de consulta para outros pesquisadores como também a quantidade das obras levantadas, mais de 3 mil páginas listando aproximadamente 35 mil obras. A publicação é separada por séculos, e, ao clicar em cada nome, abre-se uma nova página com os dados básicos sobre a compositora. 
$\mathrm{O}^{\circ}$ registro (Figura I) refere-se à primeira citação ou gravação da obra, e o campo “Dúvida sobre o gênero?" se tornou necessário: o levantamento pouco antes do encerramento da pesquisa estava na casa de 7.633 compositoras, mas vários nomes comuns aos dois gêneros foram eliminados após a certificação de não se tratar de mulheres, como Alcione, Zezé ou Sirley, por exemplo. Alguns nomes femininos foram confirmados como sendo de homens, como, por exemplo, Elias D'Ângelo, cujo nome real, segundo o Escritório Central de Arrecadação e Distribuição (Ecad), é Deolinda Matos da Silva. Como vários nomes de compositoras(es) não puderam ter seu gênero certificado, a anotação foi mantida nas fichas.

\section{A. Brumatti}

\begin{tabular}{|l|l|}
\hline $\mathbf{1}^{\mathbf{0}}$ Registro & 1960 \\
\hline $\mathbf{N}^{0}$ de obras encontradas & 20 \\
\hline Dúvida sobre o gênero? & \\
\hline Estilo & Popular \\
\hline Nome completo & Amália Brumatti Ferreira Gomes \\
\hline Data Nascimento & \\
\hline Local & \\
\hline Data Falecimento & \\
\hline Local & \\
\hline Instrumento? & \\
\hline Fontes: & \\
\hline Memória Musical \\
ECAD
\end{tabular}

Figura I - Ficha de dados de compositora do século XX (MURGEL, 20I8)

Em seguida, há uma listagem das obras encontradas:

\begin{tabular}{|c|c|c|c|c|c|c|c|c|}
\hline COMPOSITORA $=$ & OBRA & NOME & PARCEIROS & $10=$ & ECAD $=$ & $\mathrm{MM}=$ & ESTILO - & GRAVAÇÕES \\
\hline A. Brumatti & A estrela Dalva & Amália Brumatti Ferreira Gomes & Canarinho & 1976 & 2003 & 1976 & & Antonieta \\
\hline A. Brumatti & Alegria de amar & Amália Brumatti Ferreira Gomes & \begin{tabular}{|l|} 
Aloísio Silva e Canarinho \\
\end{tabular} & 1961 & & 1961 & & Moacyr Franco \\
\hline A. Brumatti & Bicho da cara preta & Amália Brumatti Ferreira Gomes & Canarinho & 1960 & & 1960 & & Moacyr Franco \\
\hline A. Brumatti & Brincadeira tem hora & Amália Brumatti Ferreira Gomes & & 2006 & 2006 & & & \\
\hline A. Brumatti & Menino apaixonado & Amália Brumatti Ferreira Gomes & Canarinho & 1961 & 2006 & 1961 & & Antônio Carlos \\
\hline A. Brumatti & Meu time, meu amor & Amália Brumatti Ferreira Gomes & Canarinho & 2006 & 2006 & & & \\
\hline A. Brumatti & Mulher de verdade & Amália Brumatti Ferreira Gomes & Canarinho & 2009 & 2009 & & & \\
\hline A. Brumatti & O amor é traiçoeiro & Amália Brumatti Ferreira Gomes & Canarinho & 1962 & & 1962 & & Roberto Luna \\
\hline A. Brumatti & O bicão & Amália Brumatti Ferreira Gomes & Canarinho & 2007 & 2007 & & & \\
\hline A. Brumatti & O gato miou & Amália Brumatti Ferreira Gomes & Canarinho & 2006 & 2006 & & & \\
\hline A. Brumatti & O homem da Vila Isabel & Amália Brumatti Ferreira Gomes & Canarinho & 1968 & & 1968 & & Canarinho \\
\hline A. Brumatti & O poema da vida & Amália Brumatti Ferreira Gomes & Roberto Cópia & 1961 & 2006 & 1961 & & Trio Tamba Tajá \\
\hline A. Brumatti & Samba da Bahia & Amália Brumatti Ferreira Gomes & Canarinho & 1961 & & 1961 & & Canarinho \\
\hline A. Brumatti & Samba da curtição & Amália Brumatti Ferreira Gomes & Canarinho & 2007 & 2007 & & & \\
\hline A. Brumatti & Saudade doída & Amália Brumatti Ferreira Gomes & Canarinho & 1961 & & 1961 & & José Orlando \\
\hline A. Brumatti & Tema de Malazarte e Zé Carnêro & Amália Brumatti Ferreira Gomes & Canarinho & 1979 & 2015 & 1979 & & Canarinho e Amália Brumatti \\
\hline A. Brumatti & Tereza & Amália Brumatti Ferreira Gomes & Canarinho & 2006 & 2006 & & & \\
\hline A. Brumatti & Tu és meu grande amor & Amália Brumatti Ferreira Gomes & Canarinho & 2009 & 2009 & & & \\
\hline A. Brumatti & Twist do balanço & Amália Brumatti Ferreira Gomes & Antônio Aguillar & 1962 & 2006 & 1962 & & Canarinho \\
\hline A. Brumatti & Valsa de natal & Amália Brumatti Ferreira Gomes & Canarinho & 2007 & 2007 & $\mathrm{~N} / \mathrm{D}$ & & Canarinho \\
\hline
\end{tabular}

Figura 2 - Listagem de obras de compositora do século XX (MURGEL, 20I8) 
Das fontes consultadas, as mais utilizadas foram: Discografia brasileira em 78 rpm - I902-I964 (AZEVEDO et al., I986); Mulheres compositoras: elenco e repertório (BARONCELLI, I987); Nós, as mulheres (notícia sobre as compositoras brasileiras) (ROCHA, I986); Storia Della Musica nel Brasile: dai tempi coloniali sino al nostri giorni (I549-I925) (CERNICCHIARO, I926); Trovador: collecção de modinhas, recitativos, arias, lundús, etc. (COUTINHO, I876); e Enciclopédia da música popular brasileira: erudita, folclórica e popular (MARCONDES, I999). Dos arquivos on-line, foram consultados: Acervo Musical do Instituto Moreira Salles, Base de Dados de 78 RPM da Fundação Joaquim Nabuco (Fundaj), Base de Dados de Partituras da Fundaj, Catálogo da Editora Mangione, Catálogos de Discos e Partituras da Biblioteca Nacional, Dicionário Cravo Albin da Música Popular Brasileira, Discoteca do Centro Cultural São Paulo (Discoteca Oneyda Alvarenga), Enciclopédia Ilustrada do Choro no séc. XIX (Casa do Choro), Escritório Central de Arrecadação e Distribuição (Ecad), Hemeroteca Digital da Biblioteca Nacional, Instituto Memória Musical Brasileira, Instituto Piano Brasileiro, MPBNet e Projeto Disco de Cera.

Como os estudos de Nilcéia Baroncelli e Eli Maria Rocha, minha própria pesquisa também carrega silêncios - biografias não encontradas, nomes citados por autores como compositoras sobre os quais não encontrei rastros além dessas citações ${ }^{2}$, compositoras que assinavam como "amadoras", "uma jovem fluminense" ou "uma niteroiense" 3 , nomes reconhecidos de compositoras das quais não encontrei a obra $^{4}$, a certeza de que, como diz Virginia Woolf, muitas obras que passaram para a posteridade como anônimas ou tradição popular podem ter sido criadas por mulheres:

\begin{abstract}
[...] Quando, porém, lemos sobre uma feiticeira atirada às águas, sobre uma mulher possuída por demônios, sobre uma bruxa que vendia ervas, ou até sobre um homem muito notável que tinha mãe, então penso estarmos na trilha de uma romancista perdida, uma poeta reprimida, de alguma Jane Austen muda e inglória, alguma Emily Brontë que fazia saltar os miolos no pantanal ou careteava pelas estradas, enlouquecida pela tortura que o talento lhe impunha. De fato, eu me arriscaria a supor que Anônimo, que escreveu tantos poemas sem assiná-los, foi muitas vezes uma mulher. (WOOLF, I990, p. 63)
\end{abstract}

Imaginava, também, que a maior dificuldade se daria com as autoras de meados do século XIX ao início do século XX, mas a Hemeroteca Digital da Biblioteca Nacional foi uma fonte de pesquisa inestimável sobre elas, já que as partituras editadas eram costumeiramente enviadas ou propagandeadas pelos jornais do período, tanto nos cariocas como nos editados em Pernambuco e São Paulo.

A dificuldade maior, para minha surpresa, se deu de fato com autoras mais recentes, de meados do século XX para frente, quando as compositoras passaram a adotar nomes reduzidos que se repetem, como, por exemplo, "Ana Maria" - foram

2 Isso aconteceu especialmente em uma fonte comum a todos os dicionários sobre a canção brasileira, o livro Storia Della Musica Nel Brasile: I549-I925, de Vicenzo Cernicchiaro, publicado em I926.

3 Duas partituras na Biblioteca Nacional assinadas por “amadoras", e os pseudônimos em: Coutinho, I876, v. I.

4 Como exemplo, Beatriz Ferrão é considerada a primeira compositora brasileira, em artigos encontrados na Hemeroteca da Biblioteca Nacional e por Eli Maria Rocha, mas suas obras não são citadas. 
encontradas I4 diferentes: Ana Maria Siqueira Iório, Ana Maria Pereira Barbosa, Ana Maria Mendes da Silva, Ana Maria Pereira da Silva, Ana Maria de Souza, Ana Maria dos Santos, Ana Maria Reis Barros, Ana Maria Vilela Martins, Ana Maria da Silva, Ana Maria Vieira da Silva, Ana Maria Marcelino da Silva Nunes, Ana Maria Pereira, Ana Maria de Oliveira Espírito Santo e Ana Maria Cavalcante de Oliveira. Ana Maria Iório, parceira de Odair José em várias canções como Ana Maria, incluindo "Uma vida só (Pare de tomar a pílula)", assina depois suas canções como Diana e atualmente como Dianah.

Também surgiram dificuldades com a abreviação de nomes ${ }^{5}$ ou, ainda, quando compositoras adotaram nomes masculinos, como Alessandro ou Demétrio ${ }^{6}$. Até mesmo Dolores Duran assinou algumas composições com o nome de "Durando", lembrando que, a partir dos anos de I940, a moral burguesa estava em seu auge em relação ao recato exigido às mulheres, e uma compositora - portanto, uma "mulher pública” - não era bem-vista socialmente. Pode-se perceber um lapso de informações sobre as compositoras entre o período em que os jornais e revistas não publicam mais as notas sobre compositores em geral, limitando-se no máximo a comentar artistas consagrados, até o advento da internet, quando uma grande massa de artistas até então desconhecida consegue finalmente expor seus trabalhos. O período silenciado nas publicações acompanha a ditadura militar (início dos anos de I960) chegando até a popularização da internet, já a partir do século XXI. Percebe-se nesse período que a própria imprensa promove um “apagão cultural”, aliado ao crescimento de uma produção musical massificada centrada em sucessos fáceis e versões, facilmente observada em movimentos como a Jovem Guarda (não retirando, é preciso explicitar, seu valor e seu impacto cultural no Brasil dos anos de I960, incluindo a Tropicália) ou na canção popular romântica dos anos de I970, chegando aos ritmos populares capturados e impostos pelas grandes gravadoras e emissoras de televisão nos dias de hoje, resumidos basicamente ao sertanejo e ao funk, em que compositoras e compositores são comumente ignorados em relação aos intérpretes.

Se a indústria fonográfica e os sites sem autoria reforçam a invisibilidade das compositoras, não estão sozinhos na empreitada. Já escrevi algumas vezes sobre biografias que também reforçam essa invisibilidade, como a de Carmen Miranda, por Ruy Castro, que duvida, sem qualquer documento que fundamente sua afirmação, da autoria da letra de Carmen na pareceria com Pixinguinha de "Os home implica comigo"; do Dicionário Cravo Albin, que insinuava que as parcerias de Almira Castilho pertenciam de fato a Jackson do Pandeiro7; ou de Hermeto Paschoal, que, ao falar, em entrevista ao programa Ensaio (TV Cultura, 29 de dezembro de I990), sobre suas duas maiores influências, Luiz Gonzaga e Pixinguinha, mostra a canção "Bem-te-vi atrevido", de Lina Pesce, como sendo de autoria de Pixinguinha (cf. MURGEL, 20I6, p. 69-70).

5 Como exemplo já apresentado, A. Brumatti é a assinatura da compositora Amália Brumatti Ferreira Gomes em suas canções.

6 Marisa Vieira de Barros e Maria Lúcia Gil de San Juan Demétrio Zahra, respectivamente.

7 Recentemente, o Dicionário Cravo Albin publicou uma nova biografia de Almira Castilho, dando-lhe o crédito que merece como compositora. 
No caso de Almira Castilho, em entrevista (cf. MOURA, 200I) ela afirmou que todas as canções gravadas por Jackson do Pandeiro no período em que estiveram juntos eram dos dois, ora um assinava, ora o outro. Mas, se os biógrafos de Jackson do Pandeiro insistem apaixonadamente em creditar "Chiclete com banana" (Gordurinha e Almira Castilho) a ele, considerando a fala de Almira, deveriam também considerar que o nome dela aparecesse nas outras parcerias dos dois no período, o que obviamente não ocorre.

Os apagamentos também acontecem quando escutamos uma música de que gostamos muito sem nos perguntar quem são seus compositores, ou ainda quando as rádios dizem que a canção é só de um dos autores ou do intérprete - um exemplo disso é Anastácia, que fez as letras de muitas canções extraordinárias musicadas por Dominguinhos, como "Só quero um xodó", “Tenho sede" e "Contrato de separação". As duas primeiras, mais conhecidas, são quase sempre atribuídas somente a Dominguinhos ou eventualmente a Gilberto Gil, que gravou ambas. "Contrato de separação", gravada por Nana Caymmi, é uma das mais belas letras da compositora, em que sugere se separar da saudade. Isso ainda acontece. Alice Ruiz me contou sobre como é comum suas letras serem atribuídas somente a seus parceiros musicais, como Itamar Assumpção e Arnaldo Antunes, por exemplo. A canção “Socorro" (Arnaldo Antunes e Alice Ruiz), por exemplo, é eventualmente interpretada em verso pela poeta ${ }^{8}$, e já foram algumas vezes que o público apontou como é "linda a interpretação do poema de Arnaldo".

Outra forma de apagamento que pude perceber na pesquisa é em relação aos direitos autorais das compositoras. Uma das fontes encontradas, o catálogo digital do Ecad, reafirmou esse apagamento. Ao comparar as obras nas discografias com os registros do Ecad, notei que grande parte das compositoras sequer tem registro, incluindo as que iniciaram sua produção no século XXI, o que foi bastante surpreendente. Muitas delas tiveram seus nomes suprimidos por seus parceiros ou intérpretes no momento do registro - estão nos discos, mas desaparecem no momento da arrecadação de direitos autorais.

Um caso que pode bem registrar essa questão é o da compositora Dora Vasconcelos (I9I0-I973), uma das primeiras embaixadoras brasileiras, que se tornou amiga de Villa-Lobos nos anos de I950. As biografias encontradas contam que ela foi a ponte entre o Brasil e os Estados Unidos na divulgação da bossa nova, nos anos de I960, quando foi cônsul-geral do Brasil em Nova York. Poeta, ela fez algumas letras para canções de Villa-Lobos, como "Melodia sentimental”, “Canto triste”, “Canção de amor (Floresta Amazônica)" e "Veleiro", que foram gravadas por diversos nomes da música brasileira, como Olívia Byington, Ney Matogrosso, Teca Calazans, Elizeth Cardoso, Cida Moreyra, Mônica Salmaso e Zizi Possi, entre muitos outros intérpretes. Dessas citadas, as três primeiras constam como sendo apenas de Villa-Lobos no Ecad, "Veleiro" não está registrada, e há apenas duas canções anotando a parceria dos dois: “Sete vezes" (não encontrei gravações ou interpretações) e "Eu te amo", que teria sido interpretada por Ana Caram. Esta última, acredito que seja um erro (entre os

8 Alice gravou sua interpretação do poema no disco Paralelas, em parceria com Alzira Espíndola (Duncan Discos, 2005). 
muitos encontrados) no Ecad - Ana Caram (também compositora) interpretou "Eu te amo", de Tom Jobim e Chico Buarque, no CD The other side of Jobim, gravado nos Estados Unidos em I992.

Levando em conta a importância de Dora Vasconcelos como poeta e o fato de ser uma das poucas diplomatas brasileiras a alcançar os mais altos postos da carreira, constata-se que as canções citadas foram gravadas não só pela beleza melódica inconfundível de Villa-Lobos, mas também por suas letras. Se a família do compositor recebe seus direitos pela execução de sua obra, o mesmo não acontece com a família de sua parceira.

Com o tempo restrito da pesquisa e no intuito de compreender como é efetuado o registro no Ecad, conversei com a compositora Lucina, que me explicou que ele é realizado por uma das seguintes associações de compositores: Associação Brasileira de Música e Artes (Abramus), Associação de Músicos Arranjadores e Regentes (Amar), Associação de Intérpretes e Músicos (Assim), Sociedade Brasileira de Autores Compositores e Escritores de Música (SBACEM), Sociedade Independente de Compositores e Autores Musicais (Sicam), Sociedade Brasileira de Administração e Proteção de Direitos Intelectuais (Socimpro) e União Brasileira de Compositores (UBC). A inscrição nessas associações é gratuita, e o compositor deve enviar, além dos dados da obra e parceiros, cópias digitais das composições. É a associação escolhida que vai repassar para o Ecad as obras, assim os compositores precisam estar cadastrados e registrar toda a sua produção para garantir o recolhimento de seus direitos na execução das obras. Se o parceiro não está cadastrado em uma associação, mesmo assim seu nome deve ser registrado junto com a obra, pois dessa forma seus direitos estarão guardados, sendo pagos tão logo se liguem a alguma dessas. Um interessante estudo sobre a arrecadação de direitos autorais na canção popular foi realizado por Rita de Cássia Lahoz Morelli em sua tese de doutorado na área de antropologia, Arrogantes, anônimos, subversivos: interpretando o acordo e a discórdia na tradição autoral brasileira (MORELLI, I998), disponível no Repositório da Produção Científica e Intelectual da Unicamp9.

Outra forma de arrecadação está na gravação das composições por terceiros aqui entram as editoras, como Mangione, Irmãos Vitale e muitas outras. São elas que recebem dos cantores pela gravação das obras de seus autores. Esse sistema já deu muitos problemas, especialmente pela compra das editoras por grandes gravadoras, que muitas vezes se apropriam dos direitos dos compositores. Muitos dos autores acabaram optando por criar e administrar suas próprias editoras: Arnaldo Antunes, por exemplo, criou a Rosa Celeste; Chico Buarque, a Marola; e, entre as compositoras, Zélia Duncan criou a Duncan Edições Musicais.

Finalmente, o registro da obra pode (e deve) ser feito também na Biblioteca Nacional, no Escritório de Direitos Autorais (EDA), como propriedade intelectual mas isso é bastante oneroso aos artistas: em março de 20I7, o valor por obra registrada era de $\mathrm{R} \$ 20,00$. Por esse valor, um artista pode registrar várias canções com o mesmo autor, mas para cada parceria diferente deve haver um registro distinto. A cobrança impossibilita o registro pela maior parte das artistas - são poucas as

9 Agradeço ao parecerista deste artigo a indicação do texto, assim como suas observações pertinentes. 
compositoras que têm condições financeiras para pagar por esse serviço. Isso acaba por prejudicar o maior acervo público para pesquisa do Estado brasileiro e também os pesquisadores, já que a maior parte dos registros de canções, a partir do século XX, não serão encontrados na Biblioteca Nacional. No caso dos direitos de execução, ligados ao Ecad, foi possível perceber a quantidade de autoras que têm seus direitos lesados por parceiros, ou por intérpretes que registram sua obra em seu nome.

Se a questão do apagamento se tornou evidente com esse levantamento, outras possibilidades de recortes temáticos se evidenciaram: classe e etnia e, seguindo Foucault (I999, 200I) em História da sexualidade, sujeições e subjetivações nas construções de gênero.

No recorte de classe, é possível perceber que boa parte das compositoras populares do século XIX e início do XX são de regiões (Rio de Janeiro, Manaus, Recife, Salvador ou São Paulo) e de classes mais abastadas, como é o caso de Gina Araújo e Marília Batista, que além de compositora e cantora se apresentava ao violão nas rádios na época em que o instrumento era malvisto inclusive para os homens. Uma possível interpretação seria a de que as classes altas da sociedade do período não compactuavam com os temores das classes médias sobre a moral vigente em relação às mulheres.

Vamos encontrar também muitas compositoras negras que são lembradas nas pesquisas acadêmicas e muitas outras que ainda não foram estudadas sob o recorte étnico - Chiquinha Gonzaga é uma das mais pesquisadas, mas temos também Auta de Souza, Dona Ivone Lara, Dolores Duran, Clementina de Jesus, Lia de Itamaracá, Dalva Damiana de Freitas, Teresa Cristina, Leci Brandão, Angélica Faria, Andréa Wolff, Elza Soares, Carolina Maria de Jesus, Alaíde Costa, Tia Ciata, Almira Castilho, Carmen Silva, Carmen Costa, Negra Li, Áurea Maria, Alcione, Izzy Gordon, Clécia Queiroz, Elisa Lucinda, Elizeth Cardoso, Ellen Oléria, Zezé Motta e Leni Andrade, somente para citar algumas poucas para o volume encontrado. Inicialmente, não havia efetuado esse recorte em minha pesquisa, ele foi se evidenciando em seu andamento, mas há muito a ser estudado nesse campo.

Sobre as subjetivações e sujeições nas construções de gênero, chamou a atenção a quantidade de compositoras religiosas, em especial evangélicas, com produção muito intensa em pouco tempo, marcadamente na virada do século XX para o $\mathrm{XXI}$ e se estendendo aos dias atuais. Alguns estilos são marcados, inclusive entre as compositoras, pela repetição de discursos misóginos e de inimizade entre as mulheres, como o samba-canção, nos anos I940 e I950, e atualmente o sertanejo das vertentes mais recentes, o evangélico ligado às igrejas pentecostais e neopentecostais e também em algumas canções do funk. Torna-se evidente que há uma relação estreita entre a sociedade em que vivemos e as produções musicais de cada período, como já foi apontado por diversos pesquisadores da canção popular, como Ruy Castro, Rodrigo Faour, Zuza Homem de Mello e Lyra Neto, para citar alguns. É interessante notar que, se as resistências e subjetivações ocorriam em sambas-canções de Dolores Duran (como na ironia de "Prece de Vitalina", parceria com Chico Anysio, ou em "Fim de caso", por exemplo), Maysa ("Ouça”) e Aylce Chaves ("Lama”, parceria com Paulo Marques), a expansão dos movimentos feministas na última década tem referenciado também o funk (por exemplo, em MC Carol e Karol Conka) e o chamado "feminejo" (sertanejo femista, com Maiara e Maraísa). 
Em recente entrevista ao jornal digital Nexo, o historiador Gustavo Alonso Ferreira, autor de Cowboys do asfalto: música sertaneja e modernização brasileira, chama a atenção para as mulheres no gênero sertanejo "poderem dizer" coisas que só eram permitidas aos homens ${ }^{\mathrm{T}}$ :

Ir a motel, chorar em bar, beber até cair, dar o troco, etc. - o que é relativamente novo é o fato de a mulher falar isso também. Até porque a hegemonia da temática da "pegação" e do amor afirmativo também é relativamente nova na seara sertaneja [...]. (FERREIRA apud LIMA).

Perceber as mudanças discursivas nesses gêneros é uma interessante perspectiva para futuras pesquisas, com o cuidado, no entanto, de entender que a apropriação dos discursos de sujeição ligados ao gênero masculino pelo feminino não é feminismo - quando há a sujeição do outro, continuamos no conhecido terreno do patriarcado.

\title{
SOBRE A AUTORA
}

\begin{abstract}
ANA CAROLINA ARRUDA DE TOLEDO MURGEL é doutora em História Cultural e pesquisadora colaboradora do Departamento de História do Instituto de Filosofia e Ciências Humanas da Universidade Estadual de Campinas (IFCH/Unicamp). E-mail: acmurgel@gmail.com
\end{abstract}

\section{REFERÊNCIAS}

AZEVEDO, Miguel Ângelo de [“Nirez"] et al. Discografia brasileira em 78 rpm - I902-I964. Rio de Janeiro: Funarte, I982.

BARONCELLI, Nilcéia Cleide da Silva. Mulheres compositoras: elenco e repertório. São Paulo: Roswhitha Kempf, I987.

CASA DO CHORO. Instituto Casa do Choro. Acervo: autores. Disponível em: <http://www.casadochoro. com.br/acervo/Cards >. Acesso em: 20 jul. 2018.

CCSP - Centro Cultural São Paulo. Secretaria Municipal de Cultura. Acervo. Discoteca Oneyda Alvaren-

ga. Disponível em: 〈http://centrocultural.sp.gov.br/site/desfrute/colecoes >. Acesso em: 20 jul. 2018.

Io Vale dizer que alguns dos temas apontados pelo historiador, como "beber até cair" ou "chorar em bar", já foram cantados e compostos pelas mulheres no samba-canção há mais de 60 anos, a exemplo da já citada "Lama”, de Aylce Chaves e Paulo Marques, ou “Bar da noite”, de Bidú Reis e Haroldo Barbosa. 
CERNICCHIARO, Vincenzo. Storia Della Musica nel Brasile: dai tempi coloniali sino ai nostri giorni (I549I925). Milão: Stab. Tip. Edit. Fratelli Riccioni, I926.

COUTINHO, A. A. da Cruz. Trovador: collecção de modinhas, recitativos, arias, lundús, etc. Porto: Typ. de Antonio José da Silva Teixeira, I876.

DICIONÁRIO CRAVO ALBIN da Música Popular Brasileira. Instituto Cravo Albin. Disponível em: <http:// dicionariompb.com.br $>$. Acesso em: 20 jul. 2018.

ECADNET. Escritório Central de Arrecadação e Distribuição (Ecad). Portal para consulta dos repertórios nacional e estrangeiro de obras musicais e fonogramas cadastrados no banco de dados do Ecad. Disponível em: <https://www.ecadnet.org.br/client/app/\#/home>. Acesso em: 20 jul. 2018.

FBN - Fundação Biblioteca Nacional. Catálogo de discos. Disponível em: <http://catcrd.bn.br/scripts/ odwpor2k.dll?INDEXLIST=discos_pr:discos $>$. Acesso em: 20 jul. 2018.

. Catálogo de partituras. Disponível em: <http://catcrd.bn.br/scripts/odwpor2k.dll?INDEXLIST=partituras_pr:partituras >. Acesso em: 20 jul. 2018.

. Hemeroteca Digital Brasileira.Disponível em: 〈http://memoria.bn.br/hdb/uf.aspx >. Acesso em: 20 jul. 2018.

FOUCAULT, Michel. História da sexualidade 3: O cuidado de si. Rio de Janeiro: Graal, I999. . História da sexualidade 2: O uso dos Prazeres. Rio de Janeiro: Graal, 200I.

FUNDAJ - Fundação Joaquim Nabuco. Base de dados. Disponível em: <http://www.fundaj.gov.br/index. php?option=com_wrapper\&view=wrapper\&Itemid=34I $\rangle$. Acesso em: 20 jul. 2018.

. Partituras. Disponível em: 〈http://bases.fundaj.gov.br/partit.html〉. Acesso em: 20 jul. 2018.

GAGNEBIN, Jeanne Marie. Existência ou inexistência de uma literatura especificamente feminina. Boletim Bibliográfico Biblioteca Mário de Andrade, v. 43, n. (3/4), Prefeitura do Município de São Paulo, São Paulo, I982.

IMMUB - Instituto Memória Musical Brasileira. Disponível em: 〈http://immub.org/〉. Acesso em: 20 jul. 2018.

IMS - Instituto Moreira Salles. Acervo musical. Disponível em: 〈http://acervo.ims.com.br $\rangle$. Acesso em: 20 jul. 2018.

IPB - Instituto Piano Brasileiro. Enciclopédia. Disponível em: <http://www.institutopianobrasileiro.com. br/enciclopledia >. Acesso em: 20 jul. 2018.

LIMA, Juliana Domingos. O que é o "feminejo”. E qual o lugar das mulheres na história da música sertaneja. Nexo. I4 jan. 20I7. Disponível em: 〈https://goo.gl/gfpPyW〉. Acesso em: 20 jul. 2018.

MANGIONE. 80 anos de música brasileira. Catálogo. Disponível em: <http://www.mangione.com.br/ catalogo.html >. Acesso em: 20 jul. 2018.

MARCONDES, Marcos Antônio. Enciclopédia da música popular brasileira: erudita, folclórica e popular. São Paulo: Art Editora/Publifolha, I999.

MPBNet. Disponível em: 〈http://www.mpbnet.com.br >. Acesso em: 20 jul. 2018.

MORELLI, Rita de Cássia Lahoz. Arrogantes, anônimos, subversivos: interpretando o acordo e a discórdia na tradição autoral brasileira. Tese (Doutorado em Antropologia). Campinas: Departamento de Antropologia, Instituto de Filosofia e Ciências Humanas, Universidade Estadual de Campinas, I998. MOURA, Fernando. Jackson do Pandeiro - o rei do ritmo. São Paulo: Editora 34, $200 \mathrm{I}$.

MURGEL, Ana Carolina Arruda de Toledo. Alice Ruiz, Alzira Espíndola, Tetê Espíndola e Ná Ozzetti: produção musical feminina na Vanguarda Paulista. Dissertação (Mestrado em História). Departamento de História, Universidade Estadual de Campinas, 2005.

. "Navalhanaliga”: a poética feminista de Alice Ruiz. Tese (Doutorado em História). Departamento de História, Instituto de Filosofia e Ciências Humanas, Universidade Estadual de Campinas, 2010. 
. Mulheres compositoras no Brasil dos séculos XIX e XX. Revista do Centro de Pesquisa e Formação, n. 3. São Paulo: Sesc, 2016.

. Cartografias da canção feminina: compositoras brasileiras no século XX [... e um passeio pelos séculos XIX e XXI]. Pesquisa de Pós-Doutorado em História Cultural. Disponível em: <http://www. compositoras.mpbnet.com.br >. Acesso em: 20 jul. 2018.

PERROT, Michelle. Minha história das mulheres. São Paulo: Contexto, 2007.

PROJETO DISCO DE CERA - Arquivo Nirez. Disponível em: <http://www.projetodiscodeceranirez.com. br>. Acesso em: 20 jul. 2018.

RAGO, Margareth. Do cabaré ao lar: a utopia da cidade disciplinar - Brasil I890-I930. Rio de Janeiro: Paz e Terra, I985.

. Entre a história e a liberdade: Luce Fabbri e o anarquismo contemporâneo. São Paulo: Unesp, 2001.

ROCHA, Eli Maria. Nós, as mulheres (notícias sobre as compositoras brasileiras). Edição da autora, I986.

WOOLF, Virginia. Um teto todo seu. São Paulo: Círculo do Livro, I990. 